\section{Chemical composition and effect of an essential oil of Salix aegyptiaca (musk willow) in hypercholesterolemic rabbit model}

\author{
Isaac Karimi, ${ }^{* 1}$ Hossein Hayatgheybi, ${ }^{2}$ Tayebeh shamspur, ${ }^{3}$ Adem \\ Kamalak, ${ }^{4}$ Mehrdad Pooyanmehr, ${ }^{1}$ Yaser Marandi ${ }^{5}$ \\ ${ }^{1}$ Department of Biochemistry, Physiology and Pharmacology, School of Veterinary \\ Medicine, Razi University, Iran, \\ ${ }^{2}$ Department of Physiology, Islamic Azad University, Urmia branch, Urmia, Iran, \\ ${ }^{3}$ Phytochemistry Group, Department of Chemistry, Shahid Bahonar University of \\ Kerman, Iran, \\ ${ }^{4}$ Department of Animal Sciences, Faculty of Agriculture, Kahramanmaras Sutcu Imam \\ University, Turkey, \\ ${ }^{5}$ Department of Physiology, College of Veterinary Medicine, Urmia University, Iran.
}

Revista Brasileira de Farmacognosia Brazilian Journal of Pharmacognosy 21(3): 407-414, May./Jun. 2011

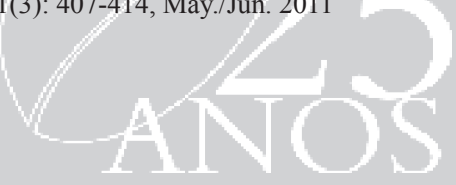

\begin{abstract}
The essential oils (EO) of Salix aegyptiaca L., Salicaceae (SA), leaves were extracted using the hydrodistillation method and their chemical composition was further determined by GC-MS. 1,4-Dimethoxybenzene was the main isolated compound. Other major isolated constitutes were phenylethyl alcohol, carvone, citronellol, methyleugenol, eugenol, $n$-tetradecane and $4^{\prime}$-methoxyacetophenone. Twenty rabbits were equally divided into four groups: Normal control (NC) which fed a standard diet and three cholesterol-fed groups: $\mathrm{HC}, \mathrm{HC}+1.0 \% \mathrm{SA}$ and $\mathrm{HC}+3.0 \%$ SA groups which received 0.0, 1.0 and 3.0\% EO, respectively for four weeks. The serum lipid and lipoprotein profiles and atherogenic index (AI) were measured weekly. The high cholesterol diet significantly raised the TC, LDL-C, VLDL-C, HDL-C, TG and AI level compared with $\mathrm{NC}$ group. $\mathrm{HC}+1.0 \% \mathrm{SA}$ and $\mathrm{HC}+3.0 \% \mathrm{SA}$ groups showed similar results compared with $\mathrm{HC}$ group. It can be concluded that the EO of SA leaves could not prevent dyslipidemia that occurred in rabbits following inclusion of cholesterol in diet in both dose-and time-dependent manners.
\end{abstract}

\section{Article}

Received 8 Jun 2010

Accepted 24 Sep 2010 Available online 4 Mar 2011

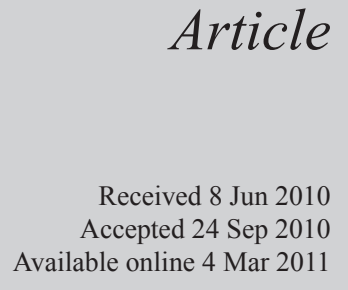

Keywords:

Salix aegyptiaca hypercholesterolemia essential oil 1,4-dimethoxybenzene

ISSN 0102-695X doi: 10.1590/S0102-695X2011005000030

\section{Introduction}

Several dietary constituents of plant origin are effective cholesterol-lowering agents (Ostlund, 2004; Karimi et al., 2010). Consequently, plant foods and manufactured products rich in these phytochemicals are being promoted to consumers as cardioprotective and beneficial to overall health but sometimes plants or plant products are harmful. Some plant products such as coffee (Terpstra et al., 2000), mistletoe (Viscum album, Ben et al., 2006) and marijuana seed (Cannabis sativa, Hayatgheybi \& Karimi, 2007) were reported to have hyperlipidemic and/or hypercholesterolemic effects. The level of serum lipids serves as a marker for the risk of cardiovascular disease (Castelli et al., 1992), which is a major cause of death worldwide (WHO, 2003). Therefore, it is important to understand how diet affects these risk markers. For example, two chief diterpenes, cafestol and kahweol, were reported as potent cholesterol-raising compounds in boiled coffee and coffee oil in the human diet (Urgert \& Katan, 1997).

Salix aegyptiaca L. (musk willow) is a dioecious plant belongs to the family of Salicaceae traditionally has been cultivated in Turkey, Iran, Turkmenistan and Afghanistan. There are many industrial and traditional systems that are involved in cultivating musk willow (Bidmeshk in Persian) in different regions of Iran. The aqueous extract and essential oil (EO) of Salix aegyptiaca L. (SA) are being used in confectionary and flavorful syrups. In Iranian traditional medicine, SA has been employed as laxative, cardioprotective, nervonic, sedative, hypnotic, somnolent, aphrodisiac, orexiogenic, carminative, gastroprotectant, anthelmintic and vermifuge. The decoction of leaves or barks of SA have been used as an anthelmintic and vermifuge remedy. The decoction of SA's leaves in honey still is used as a nervonic functional food. The decoction of leaves of SA plus sugar has been used among Iranian and Turkish people for maladies like depression, neuropathic pain and rheumatoid arthritis.

The Salix family is famous due to its endogenous salicylate compounds e.g., salicylic acid and acetyl salicylic acid (ASA, Aspirin ${ }^{\circledR}$ ). This class of compounds exert anti-inflammatory effects throughout the inhibition of cyclooxygenase-1 (COX-1) and cyclooxygenase- 2 (COX-2) leading to the inhibition of prostaglandin 
synthesis (Yu et al., 2002; Mahdi et al., 2006). The antiinflammatory and anti-nociceptive properties of extracts of willow family may be related to its phytochemicals such as salicin, myricetin, kaempferol, quercetin, rutin and luteolin (Qin \& Sun, 2005; Nahrstedt et al., 2007). These compounds have immunomodulatory and antiinflammatory activities by inhibiting pro-inflammatory cytokine production and their receptors (Qin \& Sun, 2005; Nahrstedt et al., 2007). The considerable myricetin, rutin and catechin content of musk willow extracts could potentially contribute to the anti-inflammatory functions of willow extracts (Enayat \& Banerjee, 2009).

According to Unani medicine, SA has warm humor nature and ethnic herbalists prescribed it for cholelithiasis, cholecystitis, arthritis and rheumatism. The EO of SA is febrifuge and is dubbed among Iranian people for its calming effect on heart and possibly its antihypertensive effect. Hence, in this study, we investigate the effect of Musk willow EO on lipid profile in cholesterol-fed rabbits.

\section{Material and Methods}

\section{Plant collection and authentication}

The leaves of SA were purchased from the Ghamsar botanical garden at Kashan, Iran and air dried in the shade. It was authenticated by Dr Abbas Siami, Professor of Botany in Department of Biology, College of Science, Urmia University, Iran.

\section{Extraction}

Fresh SA leaves $(150 \mathrm{~kg})$ were changed into the distillation unit along with $600 \mathrm{~L}$ fresh water. The unit was heated by steam water. The process was followed to collect of $450 \mathrm{~L}$ of distilled SA water. Liquid-liquid extraction procedure: $5 \mathrm{~mL}$ of each extractor solvent (n-hexane, dichloromethane and chloroform) mixed with $500 \mathrm{~mL}$ of SA water that was saturated by sodium chloride, then shook for $15 \mathrm{~min}$ and extracted in an ultrasonic batch for $30 \mathrm{~min}$. This procedure was repeated three times and all recovered fractions were collected. The extracted oil was dried over anhydrous magnesium sulfate and stored at $4{ }^{\circ} \mathrm{C}$ before analysis.

\section{Essential oil chemical analysis}

GC analysis was performed using a HewlettPackard chromatograph 5890 series equipped with FID detector and a HP-1 fused silica column (30 $\mathrm{m} \times 0.25$ $\mathrm{mm}$ and film thickness $0.25 \mu \mathrm{m})$. GC/MS analysis was carried out on a Hewlett-Packard 5973 connected with a mass detector HP 6890 using a HP-1 column $(30 \mathrm{~m} \times$ $0.25 \mathrm{~mm}$ and film thickness $0.25 \mu \mathrm{m}$ ). Oven temperature programming was $40-250{ }^{\circ} \mathrm{C}$ with an increase of $3{ }^{\circ} \mathrm{C} /$ min for both GC/FID and GC/MS. Injector and detector temperatures were 320 and $310{ }^{\circ} \mathrm{C}$, respectively. The carrier gas was helium and flew at a rate of $1 \mathrm{~mL} /$ min. The mass spectrometer was operated at $70 \mathrm{eV}$ with the mass range, 40-350 amu and scan time $1 \mathrm{~s}$. Identification was based on sample retention data and comparison with authentic standards, computer matching using NIST MS library. The identification was also confirmed by comparison of the retention indices with data in the literature (Adams, 1996; Shibamoto, 1987). The percentages of compounds were calculated by the area normalization method without considering response factors. The retention indices were calculated for all volatile constituents using a homologous series of $n$-alkanes.

\section{Preparation of essential oil}

The EO $(3 \% \mathrm{v} / \mathrm{w})$ was obtained from dried powdered leaves of SA by steam distillation for $3 \mathrm{~h}$, using a Clevenger apparatus. The resulting EO was diluted with distilled water to prepare $1 \% \mathrm{v} / \mathrm{w}$.

\section{Diet preparation}

Cholesterol (25 g) was dissolved in $175 \mathrm{~mL}$ ethanol and mixed with $800 \mathrm{~mL}$ sunflower oil. The resulting solution vigorously has been homogenized and immediately mixed with standard pellet (Niro-Sahand Co. Tabriz, Iran) in the ratio of $15 \% \mathrm{v} / \mathrm{w}$. The repelleted feed was air-dried under UV-illumination for two days and stored at $-5{ }^{\circ} \mathrm{C}$ until use. The resulting "high-cholesterol (HC) diet" contained in $0.47 \%$ cholesterol.

\section{Animals}

Adult weight- and age-matched healthy male Albino rabbits $(n=20)$, were maintained in an airconditioned room $\left(26 \pm 1{ }^{\circ} \mathrm{C}\right)$ and were divided into groups of five each. Group NC served as negative control that received only standard pellet and daily gavaged by $10 \mathrm{~mL}$ distilled water. Group $\mathrm{HC}$ served as positive control that received cholesterol enriched pellet and daily gavaged by $10 \mathrm{~mL}$ distilled water. Group $\mathrm{HC}+1 \% \mathrm{SA}$ received cholesterol enriched pellet and daily gavaged by $10 \mathrm{~mL}$ EO $1 \% \mathrm{v} / \mathrm{w}$ of musk willow. Group $\mathrm{HC}+3 \% \mathrm{SA}$ received cholesterol enriched pellet and daily gavaged by $10 \mathrm{~mL}$ EO $3 \% \mathrm{v} / \mathrm{w}$ of musk willow. Blood samples were collected through auricular vein on day 0 (week 0) and then at weeks $1,2,3$, and 4 . Sera were separated by centrifugation at $1400 \times \mathrm{g}$ at $4{ }^{\circ} \mathrm{C}$ for $15 \mathrm{~min}$, and stored at $-20{ }^{\circ} \mathrm{C}$ until analysis. The study was approved by the Laboratory Animal Care Committee of Urmia University, Western Azerbaijan, Iran. 


\section{Analytical procedures}

The concentrations of total cholesterol (TC), LDL-C and TGs in the serum were enzymatically determined with a commercial diagnostic kit (ELI TECH Diagnostic, French). Plasma lipoprotein fractions HDL-C were determined by immunoinhibition method (ELI TECH Diagnostic, French). Very low density lipoproteincholesterol (VLDL-C) was calculated by formula: VLDL$\mathrm{C}=\mathrm{TG} / 5$ (Friedewald et al., 1972). Atherogenic Index (AI) was calculated according to the following equation: $\mathrm{AI}=(\mathrm{TC}-\mathrm{HDL}-\mathrm{C}) / \mathrm{HDL}-\mathrm{C}$ (Lee \& Niemann, 1996).

\section{Statistical analysis}

All data are reported as mean \pm SEM. All parameters were analyzed using ANOVA for a splitplot in time design, with diet as the whole-plot factor and time (weeks) sampled as the subplot factor. This procedure allowed testing for the effects of diet and week and their interaction. When significant differences were found, post hoc comparisons were made between control and all other (treated) groups with a Duncan's multiple range tests. All data were analyzed using the General Linear Models Procedure of SPSS ver.16. Statements of significance were based on $p<0.05$ unless otherwise noted.

\section{Results}

Comprehensive GC/MS and GC/FID was used to analyze volatile components of SA leaves in this study. Figure 1 shows GC of the EO extracted from SA leaves. The chemical constituents of EO are displayed in Table 1. The main component that isolated from EO of SA in the presence of different solvents that employed in this study was 1,4-dimethoxybenzene (DMB, 1) (Table 1, Figure $1)$.

In this experiment, calories consumed and mean body weight gains were statistically similar throughout study in all groups (results not shown). Serum TC,
LDL-C, VLDL-C, HDL-C, TGs concentrations and AI levels increased significantly after 28 days of cholesterol feeding $(p<0.05$; Table 2). Concurrent administration of EO $(1 \%$ and $3 \%)$ of SA with cholesterol did not positively modify lipid and lipoprotein profiles of $\mathrm{HC}+1 \% \mathrm{SA}$ and $\mathrm{HC}+3 \% \mathrm{SA}$ groups in comparison to HC group (Table 2). No significant differences were observed in the serum levels of TC, LDL-C, HDL-C and TGs as well as $\mathrm{AI}$ between $\mathrm{HC}+1 \% \mathrm{SA}$ and $\mathrm{HC}+3 \%$ SA groups ( $p>0.05$; Table 2$)$. After four weeks, the $1 \%$ and $3 \%$ S. aegyptiaca-treated groups displayed approximately 64 and $37 \%$ of increment in VLDL-C level compared to NC rabbits, respectively $(p<0.001$; Table 2). Also, VLDL-C level were similar in $\mathrm{HC}+1 \%$ $\mathrm{SA}$ and $\mathrm{HC}+3 \% \mathrm{SA}$ groups in comparison to $\mathrm{HC}$ group (Table 2). A significant difference in the serum VLDL-C levels of cholesterol-fed groups on 1, 2, 3 and 4 weeks was observed $\left(p_{\text {ANOVA }}<0.001\right.$; Figure 2$)$.

After four weeks, the $1 \%$ and $3 \%$ S. aegyptiacatreated groups displayed approximately $28 \%$ of increment in LDL-C level compared to $\mathrm{NC}$ rabbits $(p<0.05$; Table 2). Also, LDL-C level were similar in $\mathrm{HC}+1 \% \mathrm{SA}$ and $\mathrm{HC}+3 \% \mathrm{SA}$ groups in comparison to HC group (Table 2). A significant difference in the serum LDL-C levels of cholesterol-fed groups on 1, 2, 3 and 4 weeks was observed ( $p_{\mathrm{ANOVA}}<0.001$; Figure 2 ).<smiles>COc1ccc(OC)cc1</smiles>

Inclusion of cholesterol in diet caused a significant increase $(\sim 35 \% ; p<0.05)$ in the HDL-C level compared to $\mathrm{NC}$ group while, administration of EO of $\mathrm{SA}$ could not positively improve this parameter in both of the $\mathrm{HC}+1 \% \mathrm{SA}$ and $\mathrm{HC}+3 \% \mathrm{SA}$ groups in comparison to $\mathrm{HC}$ group (Table 2). A significant difference in the

Table 1. Comparative chemical composition (\%) of the essential oil of Salix aegyptiaca L. (Egyptian willow) in the presence of different solvents.

\begin{tabular}{lcccc}
\hline \multicolumn{1}{c}{ Compound (\%) } & Dichloromethane & Chloroform & Hexane & RI* $^{*}$ \\
\hline Phenylethyl alcohol & 10.9 & 13.7 & 0.6 & 1002 \\
1,4-Dimethoxybenzene & 56.6 & 54.4 & 61.5 & 1050 \\
Carvone & 5.4 & - & 6.0 & 1118 \\
Citronellol & 5.0 & - & 8.0 & 1121 \\
4'-Methoxyacetophenone & 3.0 & 3.0 & 0.9 & 1204 \\
Eugenol & 1.9 & 6.0 & 2.0 & 1229 \\
Metheleugenol & 2.5 & 21.0 & 3.0 & 1287 \\
\hline
\end{tabular}

*RI: retention indices in elution from HP-1 column. 


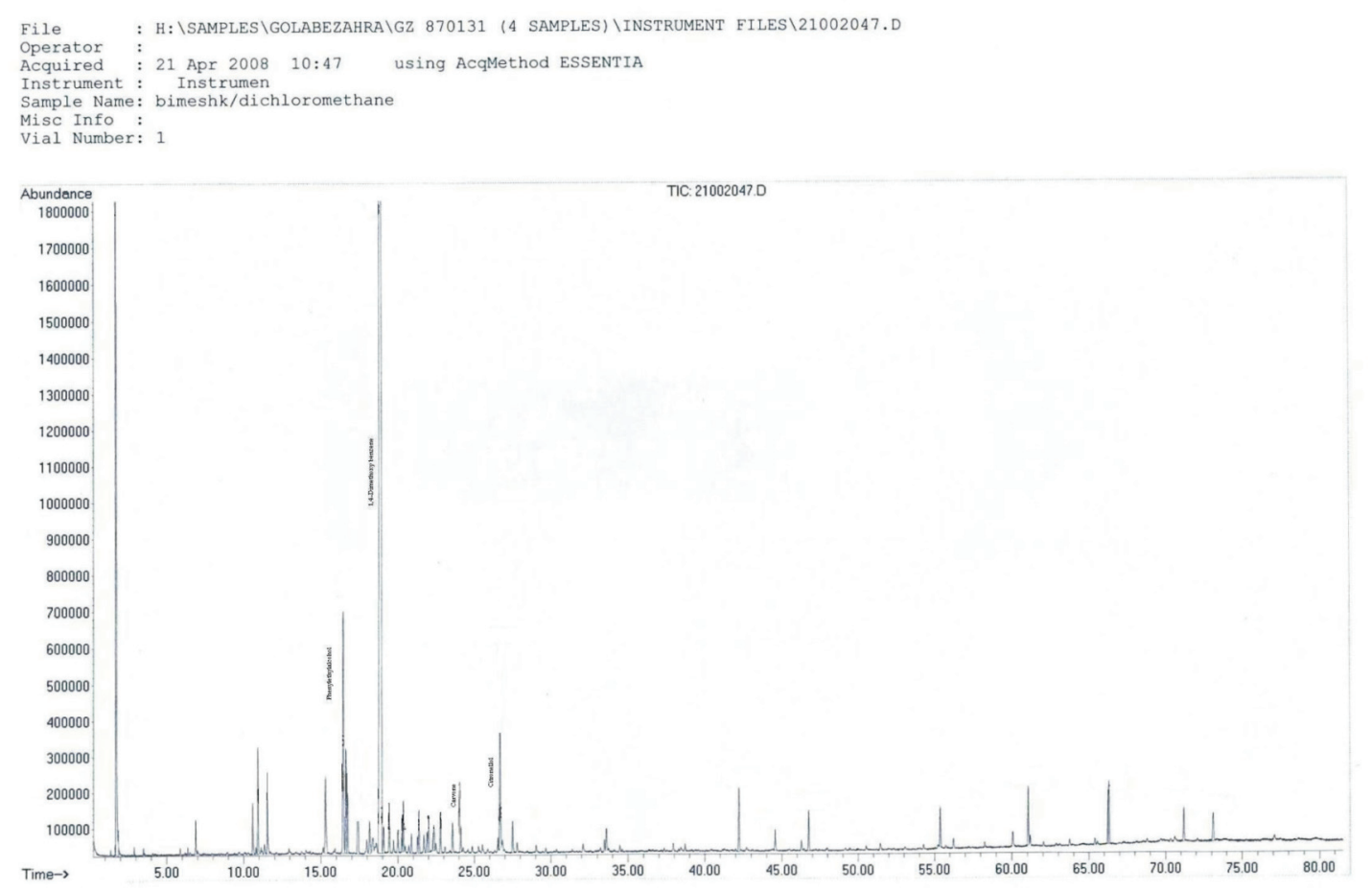

Figure 1. GC chromatogram of the essential oil extracted from Salix aegyptiaca L. leaves by dichloromethane. The main compounds represented from left to right on the chromatogram are phenylethylalcohol, 1,4 dimethoxybenzene, carvone and citronellol, respectively.

Table 2. Effect of essential oil of Egyptian willow on lipid profile and atherogenic index (AI) in cholesterol fed rabbits.

\begin{tabular}{lcccccc}
\hline \multicolumn{1}{c}{ Group } & TC & LDL-C & VLDL-C & HDL-C & TG & AI \\
\hline $\mathrm{NC}$ & $59.04 \pm 1.02 \boldsymbol{1}^{\dagger}$ & $25.84 \pm 0.76 \dagger$ & $13.12 \pm 0.510 \dagger$ & $17.64 \pm 0.637 \dagger$ & $62.20 \pm 2.588 \dagger$ & $2.37 \pm 0.094 \dagger$ \\
$\mathrm{HC}$ & $92.32 \pm 3.996^{*}$ & $39.28 \pm 1.534^{*}$ & $21.39 \pm 1.381^{*}$ & $24.44 \pm 1.642^{*}$ & $106.08 \pm 7.093^{*}$ & $2.94 \pm 0.118^{*}$ \\
$\mathrm{HC}+1 \% \mathrm{SA}$ & $92.92 \pm 3.981^{*}$ & $39.62 \pm 1.561^{*}$ & $21.56 \pm 1.398^{*}$ & $24.12 \pm 1.607^{*}$ & $107.92 \pm 6.841^{*}$ & $3.03 \pm 0.130^{*}$ \\
$\mathrm{HC}+3 \% \mathrm{SA}$ & $92.96 \pm 3.985^{*}$ & $39.00 \pm 1.400^{*}$ & $18.05 \pm 0.761^{*}$ & $23.28 \pm 1.546^{*}$ & $107.36 \pm 6.943^{*}$ & $3.12 \pm 0.133^{*}$ \\
\hline
\end{tabular}

Values are mean \pm SEM $(n=5) ;$ Data in columns were significantly different at $\mathrm{p}<0.05$ compared to NC: Normal control; $\uparrow$ Data in columns were significantly different at $p<0.05$ compared to HC: Hypercholesterolemic control. $\mathrm{HC}+1 \% \mathrm{SA}$ and $\mathrm{HC}+3 \%$ SA groups received 1 and $3 \%$ essential oil of Egyptian willow plus atherogenic diet, respectively.

serum HDL-C levels of cholesterol-fed groups on 1, 2, 3 and 4 weeks was observed ( $p_{\text {ANOvA }}<0.001$; Figure 2$)$. A significant increment $(\sim 55 \% ; p<0.05)$ in the circulating TC was detected in all cholesterol-fed groups and EO of SA could not prevent of this accrual effect in both levels of 1 and 3 percent in S. aegyptiaca-treated groups. The levels of TC in cholesterol-fed groups were changed in parallel to the levels of its composed fractions: HDL-C and LDL-C (Table 2). A significant difference in the serum TC levels of cholesterol-fed groups on 1, 2, 3 and 4 weeks was observed ( $p_{\text {ANOVA }}<0.001$; Figure 2$)$.

In comparison to NC group, the TGs also increased to a significant level $(p<0.001)$ by $75 \%$ in cholesterol-fed groups. A significant difference in the serum TG levels of cholesterol-fed groups on 1, 2, 3 and 4 weeks was observed ( $p_{\text {ANOVA }}<0.001$; Figure 2$)$. With respect to NC group, AI also showed an increase of 24.0,
27.8 and 31.6 percent in $\mathrm{HC}, \mathrm{HC}+1 \% \mathrm{SA}$ and $\mathrm{HC}+3 \% \mathrm{SA}$ groups, respectively $(p<0.05$; Table 2$)$. The concurrent administration of EO of SA did not improve AI in rabbits and increased it by $3 \%$ percent in $\mathrm{HC}+3 \%$ SA compared to $\mathrm{HC}+1 \%$ SA groups ( $p>0.05$; Table 2$)$.

\section{Discussion}

The essential oil of Salix aegyptiaca L. did not improve lipid profile and possibly it was mildly atherogenic because AI increased following intake of SA despite the existence of lipid-lowering agents like eugenol and citronellol in EO of SA (Holmes \& DiTullio, 1962; Germán et al., 1998). A possible explanation for lack of the anti-atherogenic effect of EO of SA related to its sedative, hypnotic and somnolent effects that lead to a sedentary behavior followed by increasing blood 

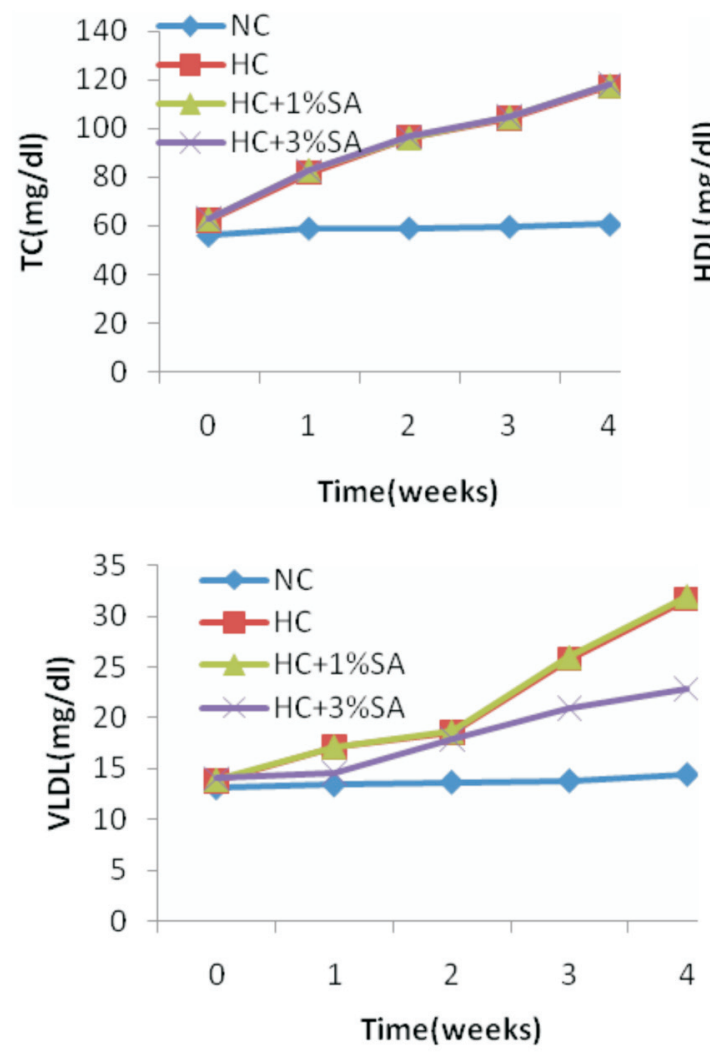
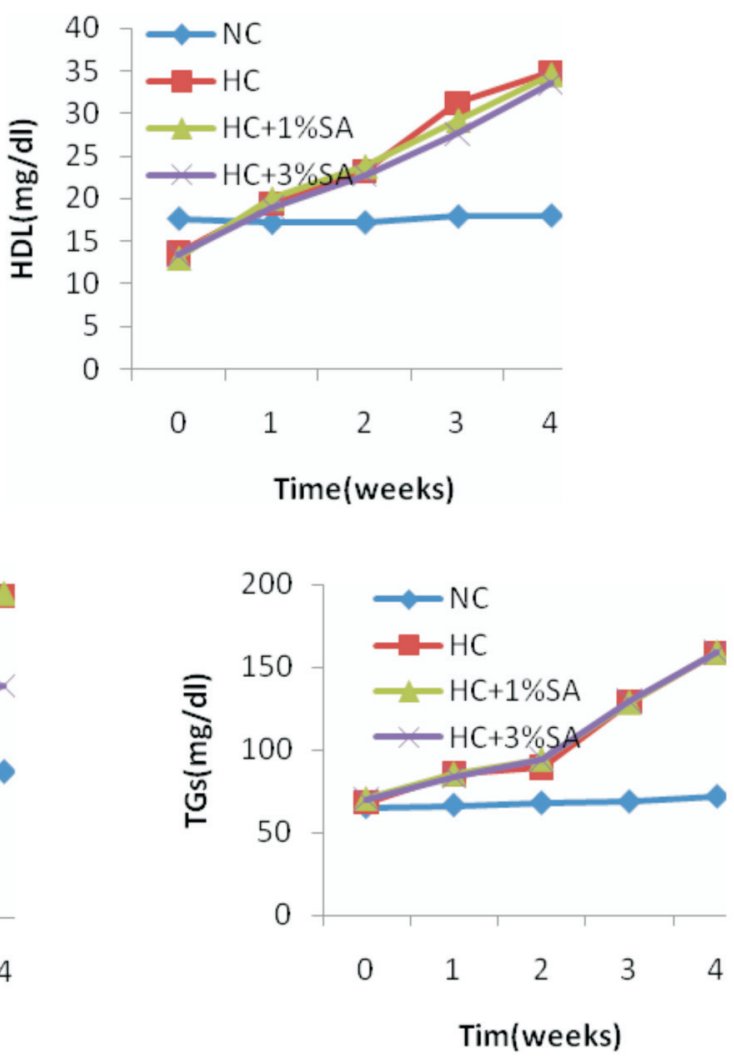

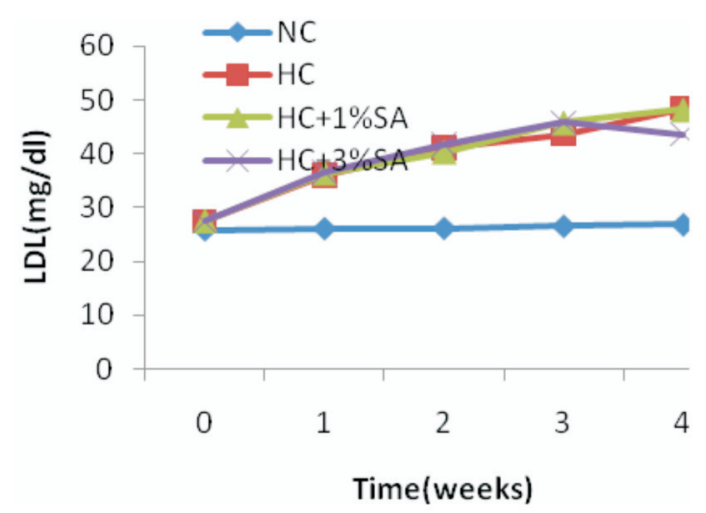

Figure 2. Lipid profiles at 0,1,2, 3 and 4 week of treatment with 1.0 and 3.0\% essential oil of Salix aegyptiaca L. in HC+1\% SA and $\mathrm{HC}+3 \% \mathrm{SA}$, respectively compare with Normal Control (NC) and Hypercholesterolemic Control (HC).

cholesterol and disturbing of lipid profile (Wijndaele et al., 2009).

We found higher amounts of DMB, citronellol, carvone and metheleugenol in EO of SA that isolated by $n$-hexane in comparison to the values reported by Babakhanlo et al., 1999. The amounts of dodecane, phenylethyl alcohol, tetradecane and eugenol were higher in our studied variety compared with the amounts that found in the EOs of SA from Research Institute of Forests and Rangelands, Iran (Babakhanlo et al., 1999). 1,4-Dimethoxybenzene also known as "hydroquinone dimethyl ether" is the para form of dimethoxybenzene, a volatile aromatic ether with a sweet floral odor. It occurs naturally in willow (Salix spp.; Dötterl et al., 2005) and Zuchini (Cucurbita pepo; Mena Granero et al., 2005). The remarkable behavioral change that has been reported following intake of DMB in mice was somnolence as a general depressed activity (Sigma Aldrich, 2004). DMB known as poison by intraperitoneal route, moderately toxic by ingestion and as a skin irritant (Sigma Aldrich, 2004). DMB was identified as the major psychoactive chemical in musk willow in the present study.

Carvone, as a monoterpene was found naturally in caraway (Carum carvi) and dill (Anethum graveolens; 
De Carvalho et al., 2006). Carvone, as a major volatile compound in different parts of Anethum graveolens, was reported in higher amounts (28-60\%; Hajhashemi \& Abbasi, 2008; Leung \& Foster, 1996) compared with $6 \%$ in $A$. aegyptiaca in our study. Terpenoid compounds of EO of SA such as carvone may have potential of cholesterol-raising effect in long term intake. In this sense, cafestol and kahweol are lipid-raising diterpenes present in unfiltered coffee (Boekschoten, 2004). Another most active monoterpene of EO of SA, citronellal, also was shown to inhibit in vitro synthesis of cholesterol from mevalonate (Holmes \& DiTullio, 1962). However, this monoterpene, when administered orally to rats $(0.5$ $\mathrm{mg} / \mathrm{kg}$.) for four weeks, had no effect on liver and serum cholesterol level (Holmes \& DiTullio, 1962). Eugenol and eugenol acetate are two main components of EO extracted from Melissa officinalis leaves (Aliabadi et al., 2009). The myorelaxant, antispasmodic, antioxidant and hypolipidemic effects of eugenol have been reported (Germán et al., 1998; Lima et al., 2000; Lahlou et al., 2004). Eugenol as an antioxidant could inhibit LDL-C oxidation, thereby preventing atherosclerosis (Rajalakshmi et al., 2000; Teissedre \& Waterhouse, 2000; Trevisan et al., 2006; Steinberg, 1995; Ito et al., 2005). LDL-C oxidation was increased in rabbit fed with $\mathrm{HC}$ diet for eight weeks (Özsoy \& Pabuçcuolu, 2007). Low level of eugenol in the EO of SA seems to be insufficient to improve lipid profile e.g., level of cholesterol in the present study.

The result of this study support that EO of SA has not therapeutic and/or prophylactic effects against incoming dyslipidemia in rabbits. The EO of SA contains several serum lipid improving phytochemical ingredients such as eugenol and citronellol (Holmes \& DiTullio, 1962; Germán et al., 1998). However, the other chemical ingredients in EO of SA might participate in the phenomena that hasten atherogenesis. In Iranian ethnomedicine, SA has been prescribed for ailments like cholecystitis and cholelithiasis may be due to inhibition of bile acid synthesis or antimicrobial effects of its active components like phenylethyl alcohol. Phenylethyl alcohol showed antibacterial activity against a wide range of bacteria such as Pseudomonas fluorescens, Staphylococcus aureus, Enterococcus faecalis, Mycobacterium smegmatis and Mycobacterium phlei (Fraud et al., 2003).

With respect to the lipid profile, our results suggested a time-dependent increase in the plasma TC level in all cholesterol-fed groups. This result is consistent with previous report that the TC increases with age (Chatterjea \& Shinde, 2002). However, this increase in TC in S. aegyptiaca-treated groups could be mainly due to the lake of protective effects of the EO of SA and not due to age, since the TC was also increased as early as the first week of EO administration. A significant increase in plasma level of HDL-C was also observed.
This increase in HDL can solely be responsible for the observed increase in TC since the EO might be affecting the HDL metabolism in the liver (Eder \& Gidez, 1982). In this experiment, $0.47 \%$ cholesterol load to the animals could generate hypercholesterolemia. Studies in both animals and humans have demonstrated that prolonged high cholesterol concentration in the circulating blood positively correlates with developing atherosclerosis (Pratico, 2001; Kurosawa et al., 2005). These changes are associated with the phenomenon that excessive load of cholesterol to the liver, above the acceptable level of its normal physiological limit, causes the liver to be unable in metabolizing the lipids, thus resulting in high cholesterol return in the circulating blood (Kushi et al., 1996). In this study, however, the treatment of high cholesterol fed animals concomitantly with EO of SA showed not protective effect against hypercholesterolemia and hypertriglyceridemia. Atherosclerosis is an inflammatory disease (Ross, 1999). The Salix spp. were dubbed for their anti-inflammatory effects both in traditional and orthodox medicines (Mahdi et al., 2006). However, the EO of SA in the current study did not prevent from cholesterol-induced atherogenesis because AI has not been improved following intake of EO of SA. It is widely known that both the liver and heart are at risk in patients with hypercholesterolemia. Hypercholesterolemic diet feeding induces oxidative stress to injure the liver and heart (Suanarunsawat et al., 2010).

\section{Conclusion and perspectives}

Administration of essential oil of Salix aegyptiaca L. in hypercholesterolemic rabbits could not prevent from occurring of dyslipidemia. More studies are needed to determine the mechanism(s) of effect of musk willow and its active ingredients on cholesterol and triglyceride metabolism in normal physiology. Because of the mixture of bioactive components present in the essential oil of musk willow, it is possible that more than one mechanism underlying this accrual effect on atherogenic index is involved. The investigation of the effects of essential oil of musk willow and its major compound, 1,4dimethoxybenzene, in normocholesterolemic condition is our future endeavor.

\section{Acknowledgements}

This study was financed partly by the College of Veterinary Medicine, Urmia University, Urmia, Iran, which did not contribute to the design, analyses or preparing of manuscript. 


\section{References}

Adams RP 1996. Identification of essential oil components by gas chromatography mass spectroscopy, Allured Publishing Corporation, Carol Stream, IL.

Aliabadi Farahani H, Valadabadi SA, Daneshian J, Khalvati MA 2009. Evaluation changing of essential oil of balm (Melissa officinalis L.) under water deficit stress conditions. J Med Plant Res 3: 329-333.

Babakhanlo P, Mirza M, Sefidkon F, Ahmadi L, Barazandeh MM, Askari F 1999. Volatile constituents of Salix aegyptiaca L., Iranian J Medicinal Aromatic Plants 2: 46-55.

Ben EE, Eno AE, Ofem OE, Aidem U, Itam EH 2006. Increased plasma total cholesterol and high density lipoprotein levels produced by the crude extract from the leaves of Viscum album (Mistletoe). Niger J Physiol Sci 21: 5560.

Boekschoten MV 2004. Elucidating the mechanism behind the lipid-raising effect of cafestol. PhD thesis, Division of Human Nutrition, Wageningen University, Wageningen, The Netherlands.

Castelli WP, Anderson K, Wilson PW, Levy D 1992. Lipids and risk of coronary heart disease. The Framingham Study. Ann Epidemiol 2: 23-28.

Chatterjea MN, Shinde R 2002. Textbook of Medical Biochemistry (5th ed.) Jaypee Brothers Medical Publishers: India p. 601-613.

De Carvalho CCCR, Da Fonseca MMR 2006. "Carvone: Why and how should one bother to produce this terpene" Food Chem 95: 413-422.

Dötterl S, Füssel U, Jürgens A, Aas G 2005. 1,4Dimethoxybenzene, a floral scent compound in willows that attracts an oligolectic bee. J Chem Ecol 31: 441445.

Eder HA, Gidez LL 1982. The clinical significance of the plasma high density lipoproteins. Med Clin North Am 66: 431-440.

Enayat S, Banerjee S 2009. Comparative antioxidant activity of extracts from leaves, bark and catkins of Salix aegyptiaca. Food Chem 116: 23-28.

Fraud S, Rees EL, Mahenthiralingam E, Russell AD, Maillard J-Y 2003. Aromatic alcohols and their effect on Gram negative bacteria, cocci and mycobacteria. J Antimicrob Chemother 51: 1435-1436.

Friedewald WT, Ley RI, Fradrickson DS 1972. Estimation of low density lipoprotein cholesterol in plasma without the use of preparative ultracentrifuge. Clin Chem 18: 499-502.

Germán C, Leticia G, Adrián S, Fermando L, Maria S, Elizdath M, Francisco D, Joaquin T 1998. Hypolipidemic activity of dimethoxy unconjugated propenyl side-chain analogs of $\alpha$-asarone in mice. Drug Dev Res 43: 105-108.

Hajhashemi V, Abbasi N 2008. Hypolipidemic activity of Anethum graveolens in rats. Phytother Res 22: $372-$
375.

Hayatghaybi H, Karimi I 2007. Hypercholesterolemic effect of drug-type Cannabis sativa L. seed (marijuana seed) in guinea pig. Paki J Nutr 6: 59-62.

Holmes WL, DiTullio NW 1962. Inhibitors of cholesterol biosynthesis which act at or beyond the mevalonic acid stage. Am J Clin Nutr 10: 310-322.

Ito M, Murakami K, Yoshino M 2005. Antioxidant action of eugenol compounds: role of metal ion in the inhibition of lipid peroxidation. Food Chem Cell Toxicol 43: 461466.

Karimi I, Hayatgheybi H, Rzmjo M, Yousefi M, Dadyan A, Hadipour M 2010. Anti-hyperlipidaemic effects of an essential oil of Melissa officinalis. L in cholesterol-fed rabbits. J Appl Biologic Sci 4: 23-28.

Kurosawa T, Itoh F, Nozaki A, Nakano Y, Katsuda S, Osakabe N, Tsubone H, Kondo K, Itakura H 2005. Suppressive effects of cacao liquor polyphenols (CLP) on LDL oxidation and the development of atherosclerosis in Kurosawa and Kusanagi-hypercholesterolemic rabbits. Atherosclerosis 179: 237-246.

Kushi LH, Folsom AR, Prineas RJ, Mink PJ, Wuv-Bustick RM 1996. Dietary antioxidant vitamins and death from coronary heart disease in postmenopausal woman. $N$ Engl J Med 334: 1156-1162.

Lahlou S, Figueiredo AF, Magalhães PJ, Leal-Cardoso JH, Gloria PD 2004. Cardiovascular effects of methyleugenol, a natural constituent of many plant essential oils, in normotensive rats. Life Sci 74: 2401-2412.

Lee R, Niemann D1996. Nutritional Assessment 2.ed: Mosby Missou USA.

Leung AY, Foster S 1996. Encyclopedia of common natural ingredients used in food, drugs and cosmetics. John Wiley and Sons: New York, p. 210-212.

Lima CC, Criddle DN, Coelho-de-Souza AN, Monte FJ, Jaffar M, Leal-Cardoso JH 2000. Relaxant and antispasmodic actions of methyl eugenol on guinea-pig isolated ileum. Planta Med 66: 408-411.

Mahdi JG, Mahdi AJ, Bowen ID 2006. The historical analysis of aspirin discovery, its relation to the willow tree and antiproliferative and anticancer potential. Cell Prolif 39: 147-155.

Mena Granero A, Egea Gonzalez FJ, Sanz JMG, Martinez Vidal JL 2005. Analysis of biogenic volatile organic compounds in zucchini leaves: identification of scent sources. J Chem Ecol 31: 2309-2322.

Nahrstedt A, Schmidt M, Jäggi R, Metz J, Khayyal M 2007. Willow bark extract: the contribution of polyphenols to the overall effect. Wien Med Wochenschr 157: 348-351

Ostlund REJr 2004. Phytosterols and cholesterol metabolism. Curr Opin Lipidol 15: 37-41.

Özsoy MB, Pabuçcuoğlu A 2007. The effect of acetaminophen on oxidative modification of low-density lipoproteins in hypercholesterolemic rabbit. J Clin Biochem Nutr 41: 27-31. 
Pratico D 2001. Lipid peroxidation in mouse models of atherosclerosis. Trend Cardiovasc Med 11: 112-116.

Qin F, Sun HX 2005. Immunosuppressive activity of Pollen Typhae ethanol extract on the immune responses in mice. J Ethnopharmacol 102: 424-429.

Rajalakshmi K, Gurumurthi P, Devaraj SN 2000. Effect of eugenol and tincture of crataegus (TCR) on in vivo oxidation of LDL+VLDL isolated from plasma of noninsulin dependent diabetic patients. Indian J Exp Biol 38: 509-511.

Ross R 1999. Atherosclerosis- an inflammatory disease. N Engl $J$ Med 340: 115-126.

Shibamoto T 1987. Retention Indices in Essential Oil Analysis, Capillary Gas Chromatography in Essential Oil Analysis. Walter Huething Verlag, New York, NY.

Sigma-Aldrich 2004. 1,4-Dimethoxybenzene; Material Safety Data Sheet.

Steinberg D 1995. Role of oxidized LDL and antioxidants in atherosclerosis. Adv Exp Med Biol 369: 39-48.

Suanarunsawat T, Devakul WNa-A, Songsak T, Thirawarapan S, Poungshompoo S 2010. Antioxidant activity and lipidlowering effect of essential oils extracted from Ocimum sanctum L. leaves in rats fed with a high cholesterol diet. J Clin Biochem Nutr 46: 52-59.

Teissedre PL, Waterhouse AL 2000. Inhibition of oxidation of human low density lipoproteins by phenolic substances in different essentials varieties. J Agric Food Chem 48: 3801-3805.

Trevisan MT, Vasconcelos Silva MG, Pfundstein B Spiegelhalder B, Owen RW 2006. Characterization of the volatile pattern and antioxidant capacity of essential oils from different species of the genus Ocimum. J Agric Food Chem 54: 4378-4382.

Terpstra AHM, Katana MB, Weusten-van der Wouw MPME, de Roos B, Beynen AC 2000. The hypercholesterolemic effect of cafestol in coffee oil in gerbils and rats. $J$ Nutr Biochem 11: 311-317.

Urgert R, Katan MB 1997. The cholesterol-raising factor from coffee beans. Annu Rev Nutr 17: 305-324.

World Health Organization 2003. The World Health Report, http://www.who.int.

Wijndaele K, Duvigneaud N, Matton L, Duquet W, Delecluse C, Thomis M, Beunen G, Lefevre J, Philippaerts RM 2009. Sedentary behaviour, physical activity and a continuous metabolic syndrome risk score in adults. Eur J Clin Nutr 63: 421-429.

Yu HG, Huang JA, Yang YN, Huang H, Luo HS, Yu JP, Meier JJ, Schrader H, Bastian A, Schmidt WE, Schmitz F 2002. The effects of acetylsalicylic acid on proliferation, apoptosis, and invasion ofcyclooxygenase- 2 negative colon cancer cells. Eur J Clin Invest 32: 838-846.

\section{*Correspondence}

Isaac Karimi

Department of Biochemistry, Physiology and Pharmacology, School of Veterinary

Medicine, Razi University, Kermanshah, Iran

karimiisaac@razi.ac.ir

Tel. +98 8318322599,8329540

Fax. +988318320041 